\title{
DESENVOLVIMENTO SUSTENTÁVEL HUMANO: UMA ABORDAGEM SOBRE A RELEVÂNCIA DOS DIREITOS HUMANOS PARA A PRESERVAÇÃO DAS FUTURAS GERAÇÕES
}

Adriana de Abreu Mascarenhas

Advogada, Doutoranda em Ciências Jurídicas pela Université de Montpellier I, França. Professora e Chefa do Departamento de Direito Privado do Centro de Ciências Jurídicas da Universidade Federal da Paraíba - UFPB.

Lorena de Melo Freitas

Professora Adjunta III e Coordenadora do Programa de Pós-graduação em Ciências Jurídicas da UFPB.

\section{Resumo}

O presente artigo será abordado em três partes. A primeira abordará os fundamentos dos direitos da pessoa humana. Os direitos humanos são muitas vezes reduzidos sobre os Direitos Civis e Políticos. Mas eles não são suficientes em si mesmos para garantir o seu acesso e permitir a todos uma vida digna. Na segunda parte, veremos como a sociedade deve garantir coletivamente, para cada um dos seus membros, às condiçóes mínimas para o exercício da liberdade pessoal. Estes são os direitos econômicos, sociais e culturais. Por fim, na última parte, veremos que a realização dos direitos humanos para todos é o propósito do desenvolvimento sustentável.

\section{Palavras-chave}

Desenvolvimento Sustentável; Sustentabilidade; Direitos Humanos; Governabilidade; Princípios; Liberdade; Dignidade; Econômico, Social; Futuras Gerações.

\section{Resumen}

Este artículo se divide en tres partes. La primera cubrirá los fundamentos de los derechos del individuo. Los derechos humanos se reducen a menudo de Derechos Civiles y Políticos. Pero no son suficientes por sí mismas para asegurar su acceso y permitir a todos una vida digna. En la segunda parte, veremos cómo la sociedad debe garantizar colectivamente para cada uno de sus miembros, las condiciones mínimas para el ejercicio de la 
libertad personal. Estos son los derechos económicos, sociales y culturales. Finalmente, la última parte, vemos que la realización de los derechos humanos para todos es el objetivo de un desarrollo sostenible.

\section{Palabras clave}

Desarrollo sostenible; Sostenibilidad; Derechos Humanos; Gobernabilidad; Principios; Libertad; Dignidad; Económico, Social; Generaciones futuras.

\section{Introdução}

As nossas sociedades baseiam-se em um contrato social implícito ou definido por uma constituição. Esse contrato social deve permitir a todos uma vida livre e digna na sociedade. Ao longo dos séculos e através das culturas, um conjunto de direitos humanos é construído e define as liberdades essenciais e as condiçóes para o seu exercício. Analisaremos agora a base e o conteúdo desses direitos, e em especial o seu desenvolvimento histórico.

Os direitos humanos são mencionados apenas uma única vez nas 240 páginas da Agenda $21(1992)^{1}$, que define as açóes para o desenvolvimento sustentável no século XXI. Na Cimeira Mundial sobre o Desenvolvimento Sustentável (Joanesburgo, 2002), os direitos humanos são uma entrada modesta como parte da boa governação. A $13^{a}$ sessão da Comissão das Naçôes Unidas sobre Desenvolvimento Sustentável (2005) questiona o direito à água, e é um texto de referência no trabalho da Comissão das Naçóes Unidas sobre os Direitos Económicos, Sociais e Culturais ${ }^{2}$.

O objetivo de Kofi Annan é o sistema das Nações Unidas que ele deseja fundado em "maior liberdade: desenvolvimento, segurança e direitos humanos para todos". ${ }^{3}$ Mas os direitos humanos são apenas uma maneira? Na melhor das hipóteses um componente do desenvolvimento sustentável? Ou é adequado tomar o quadro geral, e colocar cada item em seu lugar, observando a historicidade dos textos, mas admitiu que ele só estabelece o seu significado? ${ }^{4}$

1 Para motivar o direito à moradia: Capítulo 7, assentamentos humanos sustentáveis; 7.6 abrigo adequado para todos, base para a ação.

2 Comitê de Direitos Econômicos, Sociais e Culturais. Comentário Geral No. 15 sobre a aplicação do Protocolo Interrnacional sobre os Direitos Econômicos, Sociais e Culturais. 20 de janeiro de 2003. E / C.12/2002/11. Naçôes Unidas.

3 Relatório do Secretário-Geral para a 59ª sessão da Assembleia Geral, 24 de março de 2005, A/59/2005, das Nações Unidas.

4 Seguindo o método aqui orientação de Jean- Jacques Rousseau e o marquês d' Argenson, capítulo 2, Du Contrato Social 1762. 
O conceito de desenvolvimento sustentável vem de pensar nas consequências ambientais do desenvolvimento (Declaração de Estocolmo, 1972), mas também da necessidade de desenvolver um ambiente de convivência em que nenhum grupo humano deve ser excluído (Declaração do Rio, 1992). Tais elementos não estão presentes na Carta das Naçôes Unidas (1946). Esta se concentra na paz internacional e na dignidade humana na sequência de duas guerras mundiais, e crimes contra a humanidade, de magnitude desconhecida antes. A adoção da Declaração Universal dos Direitos do Homem (1948) deu conteúdo explícito a estes conceitos e, consequentemente definiu um assunto para as políticas nacional e internacional.

A reflexão sobre o desenvolvimento sustentável, no entanto, não se beneficiou das conquistas da implementação da Declaração Universal dos Direitos Humanos. É necessário examinar essas duas abordagens, historicamente diferenciadas, e compreender as relaçóes fundamentais. Este é o propósito da análise do tema sobre desenvolvimento sustentável em três partes.

O embasamento desta reflexão surge especialmente nos últimos tempos, com textos negociados na Organização das Naçóes Unidas, que têm a vantagem de analisar um compromisso entre visóes políticas, variedades econômicas e culturais. Por isso, é apropriado considerar o contexto histórico no qual se encaixam, tanto em termos de preocupação contemporânea aos fatos, quanto às condiçóes de poder no estabelecimento do compromisso. Consideramos, portanto, uma contribuição para nossa reflexão.

\section{Dignidade e Tolerância: Fundamentos de Direitos Humanos}

O conceito de direitos humanos é parte da história do pensamento filosófico e político. Duas questóes que são como lados que compóem a mesma moeda: a tolerância e a dignidade humana. Este é o 'como' e o 'por que' vivemos juntos.

A tolerância é o reconhecimento do outro no que é singular, diferente. É reconhecer a liberdade do outro poder ser ele mesmo, limitado pela necessidade de reconhecer a minha própria liberdade. Portanto, é evidente que o outro não é outro mim mesmo, mas reconhecendo-o com direitos idênticos aos meus.

Na Índia, no século III a.C., o imperador Ashoka proclamou:

“... Todas as crenças merecem respeito, por um motivo ou outro. Obedecendo a esse princípio, um homem homenageia suas crenças e, o mesmo movimento, ele serve as crenças dos outros".

Tais preceitos de tolerância aparecem em diferentes contextos: em Roma para os cristãos (Édito de Galerius, 311); na França para os protestantes (Édito de Nantes em 1598). 
Tolerância levanta diretamente a questão do intolerável. De um ponto de vista político, isso poderia ser considerado apenas em termos de desordem social. Mais fundamentalmente, antes mesmo de criar a constituição de uma ordem social, é necessário identificar o que é essencial para todos, e o que é intolerável para ignorar, violar para, em seguida, negar a pessoa em sua essência, ou seja, o negócio indignamente com relação ao status humano. Proibir e impedir o intolerável se torna o objeto central de uma sociedade justa. Permitir uma vida digna para todos é a base do contrato social de Jean-Jacques Rousseau, e se os métodos e meios que as sociedades humanas escolhessem para alcançá-lo pudessem ser diferentes, esse fundamento continuaria a ser comum, em que reconhecimento e satisfação são o coração progresso social.

A expressão da consciência e da liberdade, características únicas da pessoa, são os elementos essenciais de uma vida digna ${ }^{5}$. São eles que permitem que nossas escolhas de açôes e de filosofia. A possibilidade de tais escolhas deve ser socialmente reconhecida. Por conseguinte, são elas que devem ser protegidos pela tolerância.

Além disso, estas escolhas devem ser realmente possíveis: desenvolver a capacidade de exercer essas escolhas deve estar no cerne da organização social, para que todos possam se beneficiar do "contrato social", além do reconhecimento de cada ser humano e elementos de sua liberdade.

Note aqui que este contrato social é o oposto da lei da natureza, que vê antes de tudo o triunfo do mais forte, este mais forte que dispóe de mais capacidade e meios a priori, e que poderá exercer as suas capacidades eventualmente subjulgando os outros, isto é, removendo-lhes a possibilidade de escolher.

Tal como vemos aqui, os direitos humanos aparecem antes da construçáo da lei que vem regular as relaçóes entre as pessoas, e as relaçóes entre as pessoas e entidades coletivas dentro do contexto do "contrato social". Assim, nesse sentido, a denominação jurídica dos direitos não se aplica formalmente para os Direitos Humanos. Eles são o reconhecimento de valores fundamentais, e, portanto, vão ser restringidos dentro do sistema jurídico.

\subsection{Considerações Históricas sobre as Declarações de Direitos Humanos}

Os Direitos Humanos, Direitos do Homem, ou Direitos da Pessoa Humana, são direitos que todo ser humano possui, sendo universal, inalienável, independentemente do direito positivo ou outros fatores locais, tais como etnia, nacionalidade ou religião.

5 Jeanne Hersch enfatiza a singularidade do homem que está consciente do mundo e, portanto, deve agir em conformidade com esssa consciência. 
De acordo com esta doutrina, contrária no século XIX, no século XX e no século XXI por outras doutrinas, cada ser humano - e, como tal, independentemente do status social - tem direitos “inerentes à sua pessoa, inalienáveis e sagrados” e, portanto, exequível em todas as circunstâncias para a sociedade e poder.

Assim, o conceito de direitos humanos é uma definição universal e igualitária, incompatível com os sistemas e regimes baseados na superioridade ou "missão histórica" de uma casta, de uma raça, de um povo, de uma crença, de uma classe ou de qualquer grupo social ou individual; igualmente incompatível com a ideia de que a construção de uma sociedade melhor justifica a eliminação ou a opressão daqueles que são supostamente para impedir tais construçóes.

A Persia é considerada a origem do conceito de direitos humanos, no século VI a.C. $\mathrm{AD}$, no reinado de Ciro, o Grande. Após a conquista da Babilônia em -539, o rei fez executar o Cilindro de Ciro, descoberto em 1879, por vezes referido como a "primeira carta de direitos humanos" (BRIANT, 1996). Em 1971, as Nações Unidas (ONU) a traduziu em todas as línguas oficiais.

O cilindro decretou temas normais de domínio persa: tolerância religiosa, abolição da escravatura, a liberdade de escolha da profissão e do império expansão. Ele está localizado na tradição mesopotâmica com o ideal do justo rei, o primeiro exemplo conhecido é o de Urukagina rei de Lagash, que governou no século XXIV a.C. BC. Um outro exemplo representativo é o de Hamurabi da Babilônia, com o seu código que data do século XVIII BC. AD. A inscrição de Ciro, no entanto, apresenta algumas características inovadoras, incluindo as decisões sobre a religião (BRIANT, 1996).

Este documento traça os eventos que precedem a tomada da Babilônia. Ciroo Grande, em seguida, expóe as decisóes para os babilônios: "ele reina pacificamente e libera algumas tarefas pessoais consideradas abusivas, dá às pessoas deportadas o direito de regressar aos seus países e deixa as estátuas originais de divindades, uma vez tomadas para Babilônia de volta para seus santuários domésticos. Ele proclama completa liberdade de culto em seu império.

\subsubsection{Constituição dos Estados de Direito no Ocidente}

Formalmente, a explicação dos elementos dos direitos humanos no mundo ocidental começou na Inglaterra com a Great Charter (Carta Magna, 1215) concedida às pessoas por D. João sem Terra: "Nenhum homem livre será detido ou preso; ou despojado; ou fora da lei; ou exilado; ou de qualquer modo molestado; e nós não vamos nos apossar dele, se não no âmbito de um julgamento legal de seus pares, e de acordo com a lei do país". 
A Petição de Direitos apresentada em 1628, pelo Parlamento Inglês, introduziu o conceito do 'devido processo legal' e 'habeas corpus' em 1679 para proteger a detenção arbitrária ${ }^{6}$. Em particular, ela afirma: "o Direito está acima do Rei”

Esta declaração constitui claramente uma hierarquia de poder, enquanto aceitável na Inglaterra por causa de sua história e tradiçôes, e essencial na criação de um Estado de direito. Por outro lado, tal declaração provavelmente não teria sido possível na França, uma vez que o Estado era governado por um rei, por direito divino, ungido como um bispo durante sua consagração. Jean-Jacques Rousseau vai afirmar a sua reflexão do 'Contrato Social' (1762), como a de um cidadão de Genebra, para se libertar desse 'manto'. Com base na lei natural, ele pode muito bem, além do equilíbrio das relaçóes de poder soberano do príncipe sob seus súditos, procurar a ligação entre homens livres nas sociedades e as leis.

\subsubsection{Período Revolucionário}

O primeiro texto reconhecido que apresenta uma "declaração" dos direitos humanos é a Declaração de Independência dos Estados Unidos, em 04 de Julho de 1776. No seu segundo parágrafo, ela declara:

Queremos esclarecer, por óbvio, as seguintes verdades: todos os homens são criados iguais; são dotados pelo Criador de certos direitos inalienáveis; que entre estes direitos estão a vida, a liberdade e a busca da felicidade. Os governos são instituídos entre os homens para assegurar esses direitos, derivando seus justos poderes do consentimento dos governados.

Em poucas linhas, o essencial é expresso: o tema dos direitos humanos, a vida, a liberdade, a busca da felicidade, o papel do Estado como garantidor desses direitos e o povo, base do poder do Estado.

Em 27 de Agosto de 1789, a Assembleia Nacional do povo francês fecha as suas discussôes e adota uma "Declaração dos Direitos do Homem e do Cidadão", sob os auspícios do Ser Supremo. O Comitê de Constituiçáo de 09 de julho de 1789 tinha dado como objetivo para este texto de "tornar-se o trabalho dos representantes da nação, um guia fiel que sempre possa trazê-los de volta para a fonte da lei natural e social”.

A elaboração e a coerência do texto devem muito às reflexóes, aos trabalhos preliminares, e a linguagem da época. Às vezes, o texto é visto de forma divina ${ }^{8}$. No entanto,

6 Aplicadas de forma estrita à lei chamada "Terrorismo Bill” em 2005 e o estabelecimento de "ordens de controle".

7 No mais, perto de cerca de Meng Tzu, 300 a.C. J.C.: "O povo é o que mais importa, em seguida, vem o Estado , e o Imperador é o que importa o mínimo”.

8 A partir de 1989, decisão do ministro do Interior, a declaração é apresentada em todas as delegacias de polícia. 
udesde sua adoção, os deputados sublinham a natureza incompleta e provisória, na expectativa de um enriquecimento, após os trabalhos constitucionais ${ }^{9}$. Os trabalhos sobre este texto serão retomados, levando à criação das declaraçóes de 1793 e 1795 .

A declaração de 1789 consagra os direitos "naturais e imprescritíveis do homem. Esses direitos são a liberdade, a propriedade, a segurança e a resistência à opressão" (art. II.). Ela estabelece a participação democrática na vida política, a liberdade de opinião, a tolerância religiosa, uma justiça baseada na lei, e, finalmente, o imposto e a inspecção por parte do cidadão.

Esta declaração foi escrita num momento crucial da história do país, que tratava de afirmar a existência de um direito da pessoa humana para enfrentar o poder discricionário de um soberano ou seus representantes. A preocupação foi a mesma que impulsionou à elaboração da Carta Magna inglesa de 1215.

Quais são os limites impostos aos deputados neste contexto? ${ }^{10}$

1. O cidadão. Se o cidadão é totalmente identificado no seu papel, isso não ocorre quanto a sua qualidade. Quem são eles? mulheres, escravos, estrangeiros? A escravidão foi abolida em 1794 e restaurada em 1802, para novamente ser definitivamente abolida em 1848. As mulheres só tiveram um lugar na vida política a partir de 1944, na França. O estrangeiro naturalizado só pôde participar na vida pública, de forma reconhecida, por um curto período durante a Convenção até $1793^{11}$, e hoje o debate sobre a participação dos estrangeiros na vida pública local ainda está em discussão.

2. A liberdade. A principal preocupação da declaração é o reconhecimento de uma liberdade formal que protege contra a força do Estado, os outros cidadãos. No entanto, esta declaração não tem o objetivo explícito para permitir que todos possam ter a liberdade real, ou até mesmo para dar um papel para o Estado no cumprimento desta verdadeira liberdade, permitindo a busca da felicidade para todos, como oferece a Declaração Americana. Este texto, portanto, não requer a realização de uma sociedade melhor, mas apenas para proteger as liberdades básicas.

3. As Minorias. Finalmente, a declaração não põe em causa as minorias como grupos culturais e sociais: o seu reconhecimento, os seus direitos, etc.

9 Realizada em 27 de agosto de 1789, apresentado pelo deputado Bouche

10 Introdução aos trabalhos parlamentares relevantes de 1789 por Christine Fauré, 1988.

11 Thomas Paine, Inglês, participa do nascimento dos Estados Unidos, torna-se representante do Pas de Calais. Anacharsis Cloots, um barão prussiano também será convencional. Marat é suíço e passou muitos anos na Inglaterra antes de se estabelecer na França. 
A declaração de 1793 irá propor aditamentos: a solidariedade com os pobres, a promoção e a divulgação da educação. Elas permanecerão letra morta, e não serão incluídas na constituição 1795 , que continuará a insistir sobre os direitos e deveres, e o papel central da família.

\subsection{Declarações Revolucionárias}

Karl Marx em 'A Questão Judaica' (1843), vai fazer uma crítica a essas declaraçóes, considerando que elas estabelecem uma ordem burguesa, feita de egoísmo e garantida pela separação da esfera política e a esfera privada, como na Declaração Francesa de 1789, e na Declaração americana de 1776.

$\mathrm{Na}$ verdade nenhuma dessas declaraçôes propóe um projeto político abrangente que inclua o indivíduo e as esferas, política, econômica e social. Elas só definem as liberdades individuais e a oportunidade de participar na vida pública. A partir deste ponto de vista, estas declaraçóes podem ser lidas como propostas do pensamento liberal, com obrigaçóes mínimas do Estado, mas não ausente. As obrigaçóes do indivíduo em face à sociedade não são mencionadas. Entretanto, se por um lado entendemos a crítica de Marx como a vontade de superar as condiçóes de uma liberdade formal, propondo um projeto para uma sociedade melhor, notamos também que definir e incluir dentro de um sistema político um projeto global, poderia ser a causa dos regimes totalitários, qualquer que seja a base.

\subsubsection{Declaração Universal dos Direitos Humanos}

É precisamente em resposta ao totalitarismo e suas conseqüências, que a Declaração Universal dos Direitos Humanos foi promulgada pelas Nações Unidas em 1948, nos termos da Carta das Naçóes Unidas, incluindo o seu preâmbulo.

Essa declaração foi redigida pelo Comitê dos Direitos Humanos, nomeada pelo Conselho Econômico e Social das Naçóes Unidas, e trabalhou por 02 anos esse texto, sob a presidência de Eleanor Roosevelt ${ }^{12}$. Se a sua afiliação com a Declaração 1789 é óbvia, por outro lado, ela traz muitos elementos que lhe permitem ultrapassar os direitos civis e políticos, e introduzir uma reflexão sobre as condições de realização das liberdades.

Um dos principais redatores, René Cassin, propos a distinção de quatro pilares: direitos pessoais (vida, liberdade... e artigos 1-11), relaçóes interpessoais (família, nação, propriedade...; artigos $12 .^{\circ}$ a $17 .^{\circ}$ ), direitos políticos (liberdade de pensamento, de

12 Além de Eleanor Roosevelt, representando os Estados Unidos, a comissão incluiu René Cassin, da França; Charles Malik, do Líbano; Peng-Chun Chuang, da China. Para os membros da Comissão de Direitos Humanos, a rigor, associamos o nome de John Humphrey, então diretor da Divisão de Direitos Humanos da ONU. 
opiniaão, de associação, a vida política; Artigos 18 a 21), e finalmente, a cultura econômica, social, cujo papel para a efetividade dos direitos anteriores foi discutido anteriormente (trabalho, descanso, saúde, condiçóes de vida, educação...; artigo 22 a 28). Nessa classificação, adicionar a função específica do artigo 29, que estabelece que provem dos artigos anteriores, os deveres para o indivíduo em face da comunidade, e no artigo 30, que sublinha a indivisibilidade de todos os direitos humanos.

Este último artigo tem um papel vital no equilíbrio entre direitos - liberdades (pessoal, social, política) e os direitos que exigem que o Estado tem que criar um contexto favorável para o desenvolvimento dos direitos - liberdades individuais. Neste contexto, deve limitar as relaçóes de poder interpessoal através da estruturação das relaçóes sociais mínimas. A Declaração Universal dos Direitos Humanos, portanto, promove a relação dialética entre indivíduo-sociedade.

É lamentável, no entanto, a abordagem muito limitada dos direitos culturais neste texto. Na verdade, é apenas o direito de participar na vida cultural e de beneficiar-se da propriedade intelectual. A tolerância de práticas culturais diferenciadas, o seu reconhecimento como uma expressão de pertença a uma comunidade específica e do valor da diversidade em uma sociedade, vinculados por princípios mais amplos, são totalmente ausentes da declaração de 1948. O contexto político e a escolha dos editores, representantes dos Estados centrais têm certamente desempenhado um papel nessa perspectiva. $\mathrm{O}$ reconhecimento dos povos indígenas, e as diversidades culturais tiveram que esperar o início do século XXI: "Convenção sobre a Diversidade Cultural" da UNESCO em 20 de Outubro de 2005; e do projeto de "Declaração sobre os Direitos dos Povos Indígenas", aprovada em 30 de Junho de 2006, pelo Conselho dos Direitos Humanos. Estes direitos são essenciais porque reconhecem a legitimidade dos grupos sociais, e permitem ao homem ter direitos civis e políticos para se beneficiar da integração social e, assim, aproveitar toda a sua riqueza.

Apesar do papel reconhecido dos direitos econômicos, sociais e culturais, os países da esfera de influência soviética abstiveram-se sobre este texto, como a Arábia Saudita e África do Sul. A China, por sua vez, reconhece a declaração. Entretanto, não se deve enganar: a introdução clara sobre Direitos Econômicos, Sociais e culturais que obriga os Estados a garantirem as condiçôes para o exercício dos direitos civis e políticos é uma grande reviravolta. René Cassin ${ }^{13}$, que participou da elaboração da Constituição de 1958 na França, não incluiu o texto de 1948 nas referências constitucionais, preferindo limitar-se ao preâmbulo de 1946, e ao texto de 1789: ele vislumbrou uma fonte de muitos conflitos com o sistema jurídico francês.

13 Que lhe deu um grande número de direitos econômicos e um papel para o Estado na construção da esfera econômica. 
No contexto mais amplo da Declaração de 1948, a implementação dessas liberdades é o dever de todos e não só do legislador, como salientado no preâmbulo: “... que cada indivíduo e cada órgão da sociedade, mantendo- a constantemente no espírito, se esforcem para promover o respeito a esses direitos e liberdades".

Os procedimentos de ação pelo que não se enquadram na definição de um quadro jurídico único, mas exigem a mobilização de todos os indivíduos e todos os órgãos da sociedade (instituiçóes, organismos nacionais ou locais, culturais ou econômicos). Este é, portanto, um projeto global, mas não é um projeto ideológico ou utopia institucionalizada ${ }^{14}$. Trata-se de um conjunto de princípios que devem ser implementados simultaneamente, sem que um seja subordinado ao outro. Estes princípios permitem diferentes formas de organização da sociedade, das instituiçôes, e não são limitados por uma espiritualidade ou uma visão particular.

Uma inovação deste trabalho é declarar estes direitos "universais". Isto não estava no mandato inicial da Comissão, mas esta alegação surgiu durante a elaboração do texto. $\mathrm{O}$ ponto é essencial. Os deputados franceses foram questionados sobre a natureza universal da sua abordagem em 1789; Em 1948, depois de duas guerras particularmente cruéis por causa dos meios utilizados, mas especialmente após a implementação dos campos de extermínio nazistas pelos ideólogos que negavam a humanidade de comunidades inteiras, era necessário reafirmar o humano universal e garantir que todos pudessem agora levar uma vida livre e digna.

No entanto, ao contrário de declaraçóes anteriores que foram incorporadas por natureza como fundamento constitucional para o direito e para as instituiçóes dos Estados, o direito internacional só existe através de compromissos vinculativos em que consentem os Estados. Foi necessário aguardar os Protocolos de 1966, e aplica-los gradativamente até a entrada definitiva em vigor em 1976. Estes protocolos globais, mesmo que muitas vezes especifiquem significativamente os termos da declaração, foram gradualmente complementados por acordos, como o Estatuto dos Refugiados (1951 e 1967); contra a Discriminação Racial (1965); sobre a discriminação contra as mulheres (1979); contra a Tortura (1984); sobre os direitos dos povos indígenas como parte do trabalho (1989); sobre os direitos das crianças (1989).

Ao longo do tempo e de uma reflexão política, se encontrar no contexto particular das sociedades resultantes do feudalismo, fez com que o conceito de direitos humanos se expandisse para ir além da definição estritamente histórica. Ele adquire então um valor universal, abrangendo a reflexão filosófica sobre a dignidade humana e a tolerância, fundamentada no contrato social.

14 Um sobre os Direitos Civis e Políticos, o outro sobre os Direitos Econômicos, Sociais e Culturais. 


\section{Análise da Relação entre Direitos Econômicos, Sociais e Culturais como Fatores da Relação Humana}

Os direitos civis e políticos (reconhecimento individual, o direito à vida, direito de família, a liberdade de opinião e de expressão, participação na vida política) estão bem identificados. Eles são, muitas vezes, o ponto de referência para as declarações políticas quando se trata de "direitos humanos". Direitos econômicos, sociais e culturais são muitas vezes ignorados. No entanto, é essencial para entender no contexto desta reflexão sobre “direitos humanos e do desenvolvimento sustentável”. Na continuidade da Declaração Universal dos Direitos Humanos, encontramos o trabalho e o lazer, as condiçóes de vida (vestuário, habitação, saúde, segurança social), educação, participação na vida cultural, da paz social e internacional.

A abordagem tradicional de qualquer análise é colocar frente a frente os direitos civis e políticos, por um lado, e direitos econômicos, sociais e culturais, por outro. Esta abordagem tem sido herdada de uma visão de mundo bipolar: em primeiro lugar, um bloco "ocidental" social-democrata ou liberal economicamente, defensor dos direitos civis e políticos; segundo, um bloco comunista (incluindo países "não-alinhados") enfatizando os direitos econômicos, sociais e culturais. Em todos os casos, estas ideologias foram rápidas para repudiar os mesmos princípios que elas defendiam, especialmente em suas açóes internacionais de acordo com os seus interesses: o apoio e desenvolvimento de ditaduras, as trocas econômicas desiguais, a distribuição da riqueza em base de poder adquirido como instrumentalização de grupos populacionais... Esta dicotomia, com base em uma abordagem ideológica para o homem e a sociedade deve desaparecer hoje para ajudar a lidar com as complexidades do desenvolvimento humano. O desaparecimento dos blocos e, de alguma forma, o renascimento da história nos convidam a redefiní-la.

Os Direitos Econômicos, Sociais e culturais são elementos essenciais para lidar com as condiçóes materiais para o exercício dos direitos civis e políticos e, mais geralmente todas as atividades humanas. Estes direitos definem o acesso a bens e serviços básicos: este acesso mínimo é fixado a um nível necessário para que a dignidade e o desenvolvimento de personalidades individuais sejam respeitados. Esta é uma paráfrase do artigo 22 da Declaração Universal dos Direitos Humanos, que abre a seção sobre os direitos económicos, sociais e culturais. É também o acesso a esses direitos que garante a todos a capacidade de exercício efectivo dos direitos civis e políticos. Na verdade, o que é a liberdade de direitos sem possibilidade de alimentação, habitação, saúde, e condições mínimas de vida digna?

É justamente este conjunto de direitos econômicos, sociais, culturais, e direitos civis e políticos que definem um quadro no qual cada pessoa pode levar uma vida digna e livre, porque este conjunto oferece as liberdades individuais, as oportunidades de participaçáo social, e capacidades que permitem exercê-los. 


\subsection{Reflexões Contemporâneas que Sugerem o Elemento Essencial dos Direitos Humanos}

Finalmente, antes de fechar este capítulo sobre os fundamentos dos direitos humanos, é interessante notar que a nova luz foi dada ao final do século XX. Dois principais autores $^{15}$ devem ser citados aqui.

O filósofo John Rawls trata do interesse na justiça e na equidade como um princípio de construção do contrato social. O seu objectivo não é definir um bem a priori, independentemente do funcionamento de uma sociedade justa. Ele propóe na Teoria da Justiça (1975) que a sociedade se organize de acordo com dois princípios:

"Cada pessoa deve ter um direito igual ao mais amplo sistema de liberdades básicas, e iguais para todos, e que sejam compatíveis com o mesmo sistema para os outros. As Desigualdades sociais e econômicas devem ser dispostas de modo que ambas: a) possam ser razoavelmente esperadas para ser em benefício de cada um e; b) estejam ligadas a funçóes e posiçôes abertas a todos".

As Liberdades fundamentais para Rawls são os direitos políticos, a liberdade de expressáo, de pensamento e de consciência, integridade física e mental da pessoa, a propriedade, a proteção contra a detenção e prisão arbitrária.

O interesse do primeiro princípio é notar que existem direitos irredutíveis a que todos devem ter acesso de forma igual. Nesta área, não é permitido um meio interindividual, que permita que alguns indivíduos tenham um amplo gozo destas liberdades, enquanto outros tenham menos acesso.

Todavia, sobre o campo econômico e social, Rawls não considera que estes são direitos cujo gozo deve ser igual para todos, mas apenas que deve haver igualdade de condiçóes de acesso a esses direitos, deixando a sua distribuição ser baseada em habilidades naturais de cada indivíduo (saúde, inteligência, imaginação,...). No entanto, ele apresenta uma condição de utilização diferenciada, mas que resulta num benefício para todos. O segundo princípio, com esta cláusula de benefício compartilhado justifica as funçóes de redistribuição desenvolvidas por Rawls sobre a educação, sobre as garantias sociais em seu trabalho.

Esta abordagem liberal é fundamentada no respeito absoluto pelas liberdades individuais, bem além do utilitarismo econômico contra a qual ela é construída. No entanto, se focarmos sobre as liberdades formais, Rawls negligencia a questão da aplicação eficaz das mesmas. As regras jurídicas propostas permitem a distribuição de capacidades económicas e sociais capazes de assegurar o mesmo acesso efectivo às liberdades formais?

15 Nenhum dos dois autores faz menção explicitamente para a declaraçãode 48 . 
Amartya Sen, prêmio Nobel de Economia, interessado no subdesenvolvimento, entende o desenvolvimento como um aumento das liberdades e das capacidades necessárias para o exercício dessas liberdades. Essas capacidades devem permitir que cada um, possa escolher o seu estilo de vida, respeitando a diversidade. Nesta abordagem, Sen não aceita a redução de nenhuma capacidade, ainda que possa permitir a aumentar outra, como é necessário para cada escolha eficaz. É com base nesse pensamento que Sen fez uma série de seminários no Banco Mundial no final de 1990 para fornecer novas pistas para a ação do banco (SEN, 1999, passim).

Em comparação com a abordagem de Rawls, Sen observa que todas as categorias de "capacidade" devem ser implementadas em simultâneo para permitir a realização de uma escolha efetiva com base em aspiraçôes individuais. Por conseguinte, não aceita a ideia de dobrar as capacidades econômicas e sociais para o exercício do poder, permitido pelas diferenças na capacidade natural. ${ }^{16}$

A Reflexão de J. Rawls e de Sen têm finalidades diferentes: uma se preocupa em estabelecer uma paz justa, e a outra a dar prioridade às políticas de desenvolvimento. Ambas as abordagens conduzem ao cerne da reflexão o desenvolvimento da pessoa, de cada pessoa. Além disso, este desenvolvimento aparece necessariamente abrangendo vários componentes diferentes. Como tal, o progresso não pode ser medido em uma variável que encapsula todos esses componentes nela. Assim, a função do bem-estar coletivo dos economistas não tem relevância aqui. $\mathrm{O}$ desenvolvimento social parece ter várias dimensôes quer seja com a restrição de Rawls em relação aos direitos sociais e econômicos, ou na abordagem mais ampla de Sen. Se essas abordagens, tais como a Declaração Universal dos Direitos Humanos, parecem mais difíceis de implementar devido ao grande número de objetivos, elas oferecem várias possibilidades para construir um progresso social. Seria bom trazer esta nova perspectiva do debate sobre o desenvolvimento e crescimento ${ }^{17}$.

Finalmente, note que esses dois autores enfatizam, cada um à sua maneira, a interdependência e a irredutibilidade de direitos. Este é também o significado do artigo 30 da Declaração de 1948 que mencionamos: "Nada deve ser interpretado como o reconhecimento... qualquer direito de exercer qualquer atividade... visando à destruição dos direitos e liberdades aqui estabelecidos”. Portanto, não é de se opor aos direitos dos blocos juntos, mas encontrar uma maneira de respeitá-los todos. ${ }^{18}$

16 Aqui nós podemos fazer a pergunta do estado de desenvolvimento a que se refere implicitamente para cada autor. O reflexo de Rawls é essencialmente baseado na observação teórica de um estado rico, e de Sen sobre a prática de observação estados mais pobres.

17 O conceito de crescimento só se aplica a magnitudes de ordenadas; em um mundo multidimensional há mais relação de ordem.

18 Aqui encontramos uma abordagem necessariamente "ética" por se opor a uma abordagem "intencional" que define o objectivo a priori, para usar a análise de modelos organizacionais realizadas por Rawls. 


\subsection{Efetivação dos Direitos Econômicos, Sociais e Culturais}

A implementação dos direitos humanos é, como já discutimos antes, o compromisso de cada indivíduo, de cada órgáo da sociedade, com a certeza um papel crucial para as autoridades públicas a nível local ou Nacional. No entanto, se a observância dos direitos civis, essencialmente, requer o estabelecimento de regras para o exercício do poder público, a implementação do social, econômico e cultural geralmente requer recursos econômicos e técnicos que podem não estar disponíveis. Esses direitos podem, então, ser devidos? e em que condiçóes?

O Protocolo Internacional de Direitos Econômicos, Sociais e Culturais é prudente a este respeito. Diz em seu Art. 21. "Cada Estado membro no presente Pacto compromete-se a tomar medidas, por seus próprios esforços e através da assistência e cooperação internacional, especialmente econômica e técnica, até o máximo de seus recursos disponíveis, com vista a plena realização progressiva dos direitos reconhecidos no presente Pacto".

Os Estados têm a obrigação de implementar as políticas; para os Estados que não têm meios suficientes o recurso da cooperação é necessária e é, portanto, devida pelos Estados com estes meios. A implementação de uma política de redução da pobreza através dos "Objectivos de Desenvolvimento do Milénio para o Desenvolvimento" ${ }^{19}$ reporta diretamente a este artigo, mesmo se esta política é definida como parte do "desenvolvimento" geral. Neste contexto, para os Estados desenvolvidos um indicador deve analisar a contribuição em termos de uso destes Estados aos serviços básicos.

Em 1985, o Conselho Econômico e Social das Naçôes Unidas criou uma Comissão de Peritos para examinar relatórios dos Estados sobre a implementação dos direitos econômicos, sociais e culturais. Muito rapidamente, a Comissão teve de desenvolver uma reflexão sobre a aplicação, e para definir regras gerais em notas de "Comentário Geral"20. Este conjunto de observaçóes deu uma ideia das obrigaçóes dos Estados para a implementação dos direitos econômicos, sociais e culturais.

O Estado tem três formas importantes de direito: respeitar, proteger, e implementar [realizar]. É necessário náo fazer nada contra o acesso a um direito, e de proteger o que

19 Os objetivos do Desenvolvimento do Milênio foram decididos pela Assembléia Geral das Naçóes Unidas, 08 de setembro de 2000. Eles visam reduzir a pobreza em 15 anos, para promover a educação, melhorar a saúde materna, o avanço da igualdade de gênero. Eles também estão preocupados com o combate à mortalidade infantil, HIV/AIDS e outras doenças.

20 Além de comentários gerais sobre os relatórios dos Estados, deve notar-se, nomeadamente: o direito à habitação, Comentário Geral 4, 1991, sobre as expulsões forçadas, OG 7, de 1997; Primária, O.G. 11, 1999; Direito à educação, O.G. 13, 1999; Direito ao melhor estado de saúde possível, GL 14, 2000; Direito à água, O. G. 15, de 2002. 
já está feito, e, finalmente, comprometer os recursos do Estado na efetiva realização de programas de acesso. Para garantir a implementação de um direito são necessárias:

- A disponibilidade;

- A acessibilidade física e econômica, e a acessibilidade à informação;

- Aceitabilidade ética e cultural;

- A qualidade.

A disponibilidade é medida em termos de necessidades básicas.

Obviamente, a implementação desses direitos não deve conduzir a violar ou limitar um outro direito: assim, a discriminação contra uma parte da população é particularmente examinada.

No entanto, houve uma certa distância entre estes princípios gerais e sua aplicação prática no campo. A exigibilidade de direitos econômicos sociais e culturais, e, consequentemente, sua viabilidade de forma justa depende hoje das constituiçóes e leis dos Estados, sem poder recorrer a nível internacional.

No entanto, ações judiciais podem ser interessantes no contexto da implementação nacional desses direitos. Assim, em Buenos Aires, em 2003, depois de uma deportação de moradias precárias e a ocupação de um edifício, o município foi condenado pela justiça argentina a construir habitaçóes sociais, alegando o fato de que ele violou o direito uma habitação saudável.

\section{Desenvolvimento Sustentável Humano}

Os Direitos humanos devem ser vistos como uma condição necessária para alcançar o desenvolvimento sustentável, que faz parte de um bom governo. Na verdade, torná-lo real e possível a todos, é o cerne dos direitos humanos, é o coração e a própria finalidade do desenvolvimento social e do desenvolvimento sustentável.

O conceito de desenvolvimento sustentável surgiu na convergência de uma primeira corrente social consciente do impacto da atividade humana sobre o meio ambiente, e de uma segunda que desejava promover o desenvolvimento. Ele agora serve como um 'atrativo' no debate político. Sem pretender estabelecer uma definição de desenvolvimento sustentável, vamos analisar aqui duas abordagens que nos permitirá avançar em nossa reflexão:

a) A abordagem do relatório Brundtland, tal como estabelecido no Princípio 3 da Declaração do Rio: "o direito ao desenvolvimento deve ser exercido de modo a atender eqüitativamente as necessidades presentes do desenvolvimento e do meio ambiente, e também às gerações futuras." 
b) A abordagem de Ignacy Sachs, iniciador do eco-desenvolvimento na Conferência de Estocolmo, em 1992: "o desenvolvimento sustentável é uma dimensão social, ambiental e economicamente viável” ${ }^{21}$.

Ambas as abordagens nos desafiam, tanto como elas nos ajudam a entender o conceito de desenvolvimento sustentável ${ }^{22}$.

O que é este desenvolvimento no centro do desenvolvimento sustentável. Cabe aqui colocar esta abordagem em contexto. Podemos distinguir três linhas significativas.

\subsection{Desenvolvimento}

Após a Segunda Guerra Mundial, gradualmente, os impérios coloniais foram derrotados. O desenvolvimento é, portanto, uma questão fundamental para os novos governos: é para desenvolver infra-estruturas (estradas, hospitais, escolas), construir indústrias e alimentar as populaçóes em crescimento nos países em desenvolvimento. Políticas proativas, centralizadas, mais ou menos autárquicas são implementadas por esses governos. Mas eles não cumprem o sucesso esperado. Novos modelos de economia aberta são propostos, tanto no comércio internacional quanto para o capital estrangeiro. Esta abertura é acompanhada por uma demanda de reforma do Estado, sob pressão do FMI e do Banco Mundial a partir de 1981. Sáo políticas de reforma estrutural. Na esfera econômica e nos serviços essenciais (saúde, educação, segurança), o papel do Estado foi reduzido sob a pressão de serviço da dívida. Depois de várias crises, incluindo a da Argentina, o fracasso dessas políticas é óbvio, e se faz necessário encontrar novas orientações.

\subsection{Blocos Ideológicos}

Depois de Yalta, a oposição em dois blocos torna-se a estrutura do mundo, mesmo se uma terceira via é procurada pelos "não-alinhados", após a Conferência de Bandung (1955). A "polícia" internacional é gerida por cada um dos blocos, dentro de suas respectivas áreas de influência. Mas desde a queda do Muro de Berlim (1989) e o fim da URSS (1991), as áreas de influência se reestruturaram, e a maioria dos Estados ganhou autonomia política.

Neste particular foram gerados conflitos regionais de grande escala (a ex-Iugoslávia, Ruanda, República Democrática do Congo, Libéria, etc.) com base em questóes raciais, religiosas ou econômicas. A dominação dos Estados Unidos ficou mais forte através da

21 Ogunlade Davidson, co-presidente do IPCC WG III, África do Sul, descreveu o conceito de desenvolvimento sustentável como "indescritível", o que significa tanto inacessível quanto evasivo".

22 Conferência "Rio + 10", de 19 de junho de 2002. Cité de la Villette. Paris. 2002. 
construção sobre a luta contra o terrorismo na sequência dos ataques de 11 de setembro de 2001. Ela promoveu uma organização econômica liberal, em economias abertas, enquanto mostra o protecionismo nacional.

\subsection{Globalização}

Sob o impacto das tecnologias de comunicação, o baixo custo de transporte e a abertura dos blocos, a globalização das trocas de comércio se instala. Numerosos acordos internacionais são realizados para o comércio através da OMC, para a proteção do ambiente em face de questóes globais (camada de ozônio, gases de efeito estufa, alteraçóes climáticas, biodiversidade). Mas esta globalização que vê um crescimento significativo das trocas de mercado e financeiras, nem sempre beneficia a todos. Confrontada com o aumento da pobreza de certas populaçóes (países menos desenvolvidos), os "Objetivos de Desenvolvimento do Milênio" são decididos em 2000.

Neste contexto, o conceito de desenvolvimento sustentável está emergindo gradualmente em três etapas: a) 1972, em Estocolmo, a importância de ameaças ao meio ambiente é reconhecida; b) 1992, no Rio, uma perspectiva é traçada entre meio ambiente e desenvolvimento, tornando muito espaço para açôes locais e atores locais; e c) 2002, em Joanesburgo, sobre a compreensáo de como envolver a economia e seus atores nesse desenvolvimento.

Pode-se perguntar sobre o significado a ser dado para o surgimento do conceito de desenvolvimento sustentável, à luz do contexto. Se as ameaças ao meio ambiente foram o fator inicial de gatilho para a reflexáo sobre o desenvolvimento sustentável, agora devemos ver que o desenvolvimento sustentável propóe uma abordagem pragmática para programas de açôes setoriais do governo, e a ampla participação dos atores sejam eles governos locais, povos indígenas, mulheres, etc. A abordagem de "desenvolvimento sustentável", adotada pela comunidade internacional responde a uma necessidade de marcadores em um mundo que não quer reviver as abordagens ideológicas, sejam aquelas que nos levaram a regimes totalitários, ou aquelas que não puderam produzir os resultados esperados, dada a complexidade das sociedades humanas. Esta é essencialmente uma abordagem processual, ética.

O lugar explícito dos direitos ${ }^{23}$ do homem é frágil nesta abordagem, se não insignificante. Já falamos sobre a sua menção na Agenda 21. A Declaração do Rio, que fornece um quadro para a referida Agenda e para a abordagem de desenvolvimento sustentável não os menciona. No Sumário Mundial sobre o Desenvolvimento Sustentável

23 Os direitos humanos são mencionados quatro vezes nos textos. Eles foram removidos do parágrafo que define os objetivos do desenvolvimento sustentável (art.121). 
(Joanesburgo, 2002), os direitos humanos foram mencionados e discutidos repetidamente em três contextos específicos: de Responsabilidade das empresas, como parte de um contexto de desenvolvimento regional e nacional, complementando a abordagem ambiental. Além disso, a igualdade de género é mencionada.

No preâmbulo do Plano de Ação de Joanesburgo os direitos humandos são mencionados como segue:

"Art. 5०. A paz, a segurança, a estabilidade e o respeito pelos direitos humanos e liberdades fundamentais, incluindo o direito ao desenvolvimento, bem como o respeito pela diversidade cultural, são essenciais para atingir um desenvolvimento sustentável”.

Embora seja bom notar que os direitos humanos sáo mencionados apenas de forma prudente, provando que este conceito é hoje ainda a fundamentação da promoção dos valores que desafiam os poderes estabelecidos, o texto anterior mostra, ao contrário, um desrespeito pelos direitos humanos. É curioso para adicionar "liberdades fundamentais" por trás de "direitos humanos" que, precisamente por direitos civis e políticos cobrem este ponto. Será que não reverter as palavras e escrever: "o respeito dos direitos humanos e da paz, segurança, estabilidade ...”, observando bem como a paz, a segurança e a estabilidade sáo condicionadas pelo cumprimento direitos humanos?

Na Europa, uma estratégia de desenvolvimento sustentável foi adoptada no Sumário de Gotemburgo em 2001. Estes textos definem a perspectiva tomada pela Europa: "o desenvolvimento sustentável - resposta para satisfazer as necessidades do presente sem comprometer as geraçôes futuras - é um objetivo fundamental à luz dos Tratados. Isso implica que as políticas econômicas, sociais e ambientais sejam abordadas reforçando-se mutuamente". Texto de conclusão do Sumário de Gotemburgo, 15-16 junho de 2001.

Com esta decisão, nós reconhecemos a necessidade, a longo prazo, para serem aliados o crescimento econômico, a coesão social e a proteção do ambiente." Desenvolvimento sustentável para um mundo melhor. Comissáo Européia. Comunicação n. ${ }^{\circ}$ 264/2001 .

Estes dois trechos são originários das partes introdutórias dos documentos. Os direitos humanos nunca são mencionados, como irá destacar um representante de ATD Quarto Mundo nas audiências do Conselho Econômico e Social. No entanto, no corpo do documento, os objectivos de luta contra a pobreza e a exclusão, as medidas para lidar com o envelhecimento da populaçáo e aquelas concernentes à queda da segurança social, levam a implementaçáo dos direitos humanos.

Ao ler estes textos, o achatamento do desenvolvimento social, as questóes ambientais e as condições econômicas são impressionantes. O próprio desenvolvimento social é reduzido à coesão social, e o crescimento econômico é o principal objetivo. Isso reflete uma 
confusão entre fins e meios. Então, qual é o propósito de "viver juntos"? O que é o progresso social? E organização política precisa contribuir? Esses tópicos são completamente ausente das propostas do Sumário de Gotemburgo.

\subsection{Inserção os Direitos Humanos no Centro do Desenvolvimento Sustentável}

Foi demonstrado que a concepção moderna dos direitos humanos incorpora tanto o tema do desenvolvimento humano (uma vida digna e livre) como os principais componentes de sua realização (condições econômicas, sociais e culturais). Os autores da Carta das Naçóes Unidas e da Declaração Universal dos Direitos Humanos tinham compreendido a importância dos direitos humanos no centro da definição de um projeto social. $\mathrm{O}$ preâmbulo desta última vale a pena citar aqui:

Considerando que o reconhecimento da dignidade é inerente a todos os membros da família humana, e que seus direitos são iguais e inalienáveis, e constituem o fundamento da liberdade, da justiça e da paz no mundo”.

Considerando que o desprezo e o desrespeito pelos direitos humanos resultaram em atos bárbaros que ultrajaram a consciência da Humanidade, e que o advento de um mundo em que os seres humanos gozam de liberdade de palavra, de crença e da liberdade terror, e da miséria, foi proclamado como a mais alta aspiração do homem;

Considerando que é essencial que os direitos humanos sejam protegidos pelo Estado de Direito, para que o homem não seja forçado, como último recurso, à rebelião contra a tirania e a opressão...

Além disso, a abordagem de desenvolvimento sustentável enfatiza a interdependência entre a esfera social, a esfera ambiental e da abordagem econômica. Esta esfera foi proposta pragmaticamente para enfrentar os desafios do desenvolvimento e os riscos que representam para as atividades humanas em todo o nosso ambiente. Ela surge de maneira forte e estruturada, a nível internacional, nacional e local, assim como a estratégia dos agentes econômicos ${ }^{24}$.

24 Note-se que não é apenas uma questáo de meios econômicos. O Programa das Naçóes Unidas para o Desenvolvimento identificou na última década uma série de indicadores sobre o desenvolvimento, que permitem uma análise dos países. Na Índia, o Estado de Kerala aparece como um agrupamento muitos sucessos. Este resultado é devido principalmente a uma organização social, uma abordagem para o seu lugar no Estado. Esta não é objetivamente uma questão de nível econômico. Muitos exemplos obtidos por explorar sistematicamente os componentes de desenvolvimento humano estão bem documentados. Note-se que alguns países com elevado potencial econômico podem ser titulares de um desenvolvimento desequilibrado, independentemente do sistema político que eles adotaram. Os direitos humanos são mencionados quatro vezes no texto. Eles foram retirados do parágrafo que define os objectivos do desenvolvimento sustentável (art. 121.). 
No entanto, esta abordagem não tem aproveitado as realizaçóes de outras políticas e seu trabalho de implementação, especialmente aqueles que lidam com os direitos humanos.

Há uma urgência hoje para posicionar claramente essas duas abordagens.

A realização dos direitos humanos é a própria finalidade do processo de desenvolvimento sustentável, definindo claramente o propósito do desenvolvimento social. Isso é para dar a todos mais liberdade e desenvolver as capacidades de cada um.

Em primeiro lugar, as liberdades civis e políticas permitem que todos possam participar nas escolhas da sociedade em todos os níveis. Além disso, as capacidades desenvolvidas em termos de saúde, habitação, educação e trabalho permitem o exercício efectivo destas liberdades. Sem esses recursos, essas liberdades são apenas ilusóes. Deve-se enfatizar mais uma vez, fortemente, a interdependência e indivisibilidade desses direitos. Precisamos uns dos outros, cabendo aos governos e a sociedade que eles representam, para definir caminhos de desenvolvimento virtuosos assim respeitando todos os direitos civis e políticos, e direitos econômicos, sociais e culturais.

A realização dos direitos humanos também é um componente bem sucedido de políticas de desenvolvimento sustentável. Na verdade, as políticas de sustentabilidade, além da integração social, ambiental e econômica exigem, acima de tudo, a participação dos indivíduos e grupos sociais. Essa participação garante a adaptação adequada de políticas para as pessoas em causa, o que impede uma construção abstrata da realidade social. Para permitir que todos possam participar de uma maneira inteligente e informada, mas também construtiva, é necessário dispor das liberdades e capacidades definidas pelos direitos humanos.

Por fim, alcançar uma condição de desenvolvimento sustentável é uma condição de acesso a uma vida digna e livre, isto é, a realização dos direitos humanos.

$\mathrm{Na}$ verdade, como dar a todos as capacidades de implementar seus direitos em um mundo onde a qualidade do ar, os resíduos, a degradaçáo dos solos, e a qualidade da água não permitem ter uma alimentação e uma moradia saudáveis? Da mesma forma, se as trocas de mercado e os fluxos financeiros são desorganizados e desequilibrados, ou se a capacidade de tornar mais eficaz e menos doloroso o trabalho humano pela industrialização não é acessível, em seguida, a autonomia individual e capacidade física e mental para assumir esta vida digna e livre (saúde, alimentação, educação) pode estar faltando. É impossível conduzir uma vida livre e digna. No entanto, se um estado geral de destituição não goza de direitos fundamentais, ao contrário de uma economia e um ambiente saudável que irá beneficiar todos fornecidos para proporcionar um acesso geral aos serviços básicos por uma política destinada ao objetivo do desenvolvimento social e, portanto, o acesso aos direitos humanos. 
Finalmente, note a convergência das políticas adotadas para a implementação dos direitos humanos e do desenvolvimento sustentável. Ambas as abordagens não constituem uma utopia globalizada, mas propóem critérios a serem implementados. Ao desenvolver um plano de ação contra um problema específico, a pesquisa para a realizaçáo simultânea com esses critérios cria tensão entre eles e esse equilíbrio.

A abordagem dos direitos humanos e do desenvolvimento sustentável reconhecem a multiplicidade e a irredutibilidade dos objetivos esperados; elas exigem progressos em cada um dos respectivos componentes. Não se trata de um caso limitado para o desenvolvimento econômico, ou na maximização da utilidade coletiva medido pelo volume de trocas comerciais. Dada a complexidade, estas abordagens defendem uma complexa abordagem participativa, que exige uma estratégia de adaptação apoiada nas capacidades disponíveis.

Estas conclusóes alcançadas em 1948 no domínio do desenvolvimento da sociedade humana através da Declaração Universal dos Direitos Humanos, já encontraram hoje um complemento no domínio do desenvolvimento econômico e da proteção do ambiente.

Em conclusão, entendemos porque é necessário esclarecer este argumento de duas abordagens para o desenvolvimento sustentável.

A primeira, na sequência do relatório Brundtland e muitas vezes repetida, não considera o tema do desenvolvimento, mas apenas a implementação de condiçôes para o desenvolvimento sustentável, colocando no mesmo nível os objetivos, as condiçóes de execução, e os meios de execução.

A segunda: "o desenvolvimento sustentável é um desenvolvimento social, respeitando o meio ambiente e viável economicamente" permitindo estruturar a reflexão, e reposicionar o desenvolvimento social no centro da demanda do desenvlvimento sustentável, mas evidentemente sem negligenciar as condiçôes de execução e sustentabilidade deste desenvolvimento.

Assim, tornar real e acessível todos os direitos humanos é o coração e o propósito do desenvolvimento social e do desenvolvimento sustentável.

\section{Conclusões}

Duas questóes importantes, ambas as preocupaçóes atuais, duas exigências da sociedade contemporânea: Direitos Humanos e o desenvolvimento sustentável são uma parte integrante de todas as estratégias de desenvolvimento. Estes são os principais desafios para todos os países do mundo, do Norte e do Sul, nos países desenvolvidos e nos países em desenvolvimento. $\mathrm{O}$ futuro das sociedades e indivíduos com base na procura de uma forte ligação entre os dois objetivos. É um desafio contemporâneo; um desafio para o egoísmo, 
a injustiça, a desigualdade, a estreiteza mental e fraturas sociais e econômicas vivenciadas por alguns países. O tema dos direitos humanos e desenvolvimento sustentável levanta um debate profundo a nível mundial. É por estas razóes que escolhemos este tema para nosso artigo.

O objetivo do desenvolvimento sustentável é definir planos viáveis que equilibrem as três atividades humanas: ecológicas, sociais e econômicas. "Três pilares” a serem considerados tanto pelas comunidades, como por empresas e indivíduos. O objetivo do desenvolvimento sustentável é encontrar um equilíbrio sustentável consistente e de longo prazo entre estas três questóes. Para estes três pilares é adicionada uma questão transversal, cada vez mais considerado "o quarto pilar do desenvolvimento sustentável”, essencial para a definição e implementação de políticas e açóes para o desenvolvimento sustentável: governabilidade.

A governabilidade envolve a participação de todos os interessados (cidadáos, empresas, associaçôes, representantes eleitos) na tomada de decisôes; é, portanto, uma forma de democracia participativa. O desenvolvimento sustentável não é um estado estático de harmonia, mas um processo de mudança no qual a exploração dos recursos naturais, a escolha de investimentos, a orientação da mudança tecnológica e institucional são feitas de acordo com as necessidades atuais, sem prejuízo das necessidades futuras. Integrar as questóes ambientais significa adotar uma abordagem ecossistémica, baseada em princípios de gestão.

Portanto, o desenvolvimento humano sustentável é a aliança do desenvolvimento sustentável e desenvolvimento humano. Este conceito nasceu da ação humana de consciência do seu ambiente e do fato de que alguns modos de crescimento e desenvolvimento são prejudiciais ao meio ambiente. Isto permite considerar o meio ambiente como um critério adicional para ser tido em conta, além de critérios econômicos e sociais. Desenvolvimento é assim previsto a longo prazo, tendo em vista a preservação de modo que as geraçôes futuras possam viver pelo menos da mesma maneira como a nossa geração.

\section{Referências}

A ANISTIA Internacional Seção Francesa. A proteção dos direitos humanos. Ferramentas e mecanismos legais internacionais. Edição do Juris Classeurs. Paris. 2003.

ACSELRAD, H. Políticas ambientais e construção democrática. In: VIANA, G.; SILVA, M.; DINIZ, N. O desafio da sustentabilidade. São Paulo: Fundação Perseu Abramo, 2001.

ACSELRAD, Henri e LEROY, Jean P. Novas premissas da sustentabilidade democrática.

Revista Brasileira de Estudos Urbanos e Regionais, 1, 1999. BEZERRA, M. C. L.; 
ARENDT, H. A condiçáo humana. Rio de Janeiro: Forense Universitária, 2004.

BRIANT, Pierre. História do Império Persa, Ciro Alexander, Paris, 1996.

BURSZTYN, M. (cood.). Ciência e Tecnologia para o desenvolvimento sustentável. Brasília: Ministério do Meio Ambiente e dos Recursos Naturais Renováveis: Consórcio CDS/ UNB/ Abipti, 2000.

CARTA da Terra. Organizaçáo das Naçóes Unidas, 2002.

CMMAD - Comissão Mundial sobre Meio Ambiente e Desenvolvimento. Nosso futuro comum. 2ed. Tradução de Our common future. 1ed. 1988. Rio de Janeiro: Editora da Fundação Getúlio Vargas, 1991.

DUFFAR, Jean; OBERDORFF, Jean Henri. Dos Direitos Humanos e as Liberdades fundamentais. Paris: Montchrestien, coll. "Domat”. 2009.

ESCRITÓRIO do Alto Comissariado para os Direitos Humanos. Os direitos humanos, reduçáo da pobreza e desenvolvimento sustentável. Saúde, comida e água. Sumário Mundial do Desenvolvimento Sustentável. 2002.

EUZEBY, Alain. O que uma teoria da justiça social? Direitos Sociais No. 9-10, 202, In problemas econômicos, 07 de janeiro de 2004.

FAURÉ, Christine. As declaraçóes de direitos humanos de 1789. Payot Biblioteca Histórica. Paris, 1988.

GOBIN, Corinne. Os Falsificadores da Europa social. O Mundo Diplomático, outubro de 2005, pp. 10-11.

HERSCH, Jeanne. Os fundamentos dos direitos humanos na consciência universal. Os direitos humanos em questão. Comissão Nacional Consultiva dos Direitos do Homem. Documentação Francesa, Paris, 1989.

LAVILLE, Jean Louis. Com Mauss e Polanyi, a uma teoria da economia plural. A revisão do MAUSS, em problemas econômicos, 03 de setembro de 2003, pp. 17-23.

MARTIN, Jean -Yves. Desenvolvimento sustentável? Doutrinas Práticas e Avaliaçóes. IRD. 2002 .

MAURIZE, Marie-Odile. Além do Estado, o direito internacional e da Defesa dos Direitos Humanos. Ediçôes da Anistia Internacional em francês, em 1992.

. Uniáo Interparlamentar, dos Direitos do Homem. Manual para Parlamentares, Marie Odile no 8, de 2005.

O CÍRCULO Belgrado. A política de direitos humanos. Londres Verso 1999. Uma série de textos contemporâneos sobre os direitos humanos, incluindo: Rawls, Levinas, Habermas, Baudrillard Chomski. 
OFFICE of the High Commissioner for Human rights. Human rights, poverty reduction and sustainable development. Health,food and water. Background paper. World Summit on Sustainable Development. 2002.

RAWLS, John. Uma Teoria da Justiça. Teste Ponto 354. Seuil. 1997.

ROUSSEAU, Jean- Jacques. O contrato social de 1762.

SACHS, I. Desenvolvimento includente, sustentável, sustentado. Rio de Janeiro: Garamond, 2004.

. Estratégias de Transição para do século XXI - Desenvolvimento e Meio Ambiente. São Paulo: Studio Nobel - Fundação para o desenvolvimento administrativo, 1993.

SAVIDAN, Patrick. Será que há desigualdades justas? Alternativas Econômicas, 207, outubro de 2002, pp. 79-81.

SEN, Amartya. Um novo modelo econômico. Desenvolvimento. 1999.

SERGE, Antoine; BARRERE, Martine; VERBRUGGE, Geneviève. Planeta Terra em nossas máos. Guia para a implementação dos compromissos da Cúpula da Terra do planeta. Documentação francesa, 1994.

STIGLITZ, Joseph E. A Grande Desilusão. O Livro de Bolso. № 15538. Fayard. Paris. 2002. 